\title{
Effect of Anions and Related Organic Compounds on the Kinetics of Thiocyanate Oxidation in a Solar-induced Oxidative System
}

\author{
Agnia A. Batoeva*, \\ Marina R. Sizykh and Denis G. Aseev \\ Baikal Institute of Nature Management $S B R A S$ \\ Ulan-Ude, Russian Federation
}

Received 08.10.2021, received in revised form 16.11.2021, accepted 13.01.2022

\begin{abstract}
The effect of anions (hydrocarbonates, chlorides, sulfates) and organic compounds (xanthates) on the kinetics of thiocyanate oxidation in a photoinduced iron-persulfate system was studied using natural sunlight as a radiation source. It was found that the introduction of anions into the solution inhibits the degradation of thiocyanates. Hydrocarbonates have the maximum effect, so at a $\mathrm{HCO}_{3}^{-}$concentration of $1 \mathrm{mM}$, the processing time required for the complete destruction of thiocyanates increased from 6 to 15.7 minutes. At high concentrations of bicarbonates $(\geq 5 \mathrm{mM})$, the oxidation efficiency of thiocyanates does not exceed $52 \%$. The adding of butyl xanthate into the solution has no significant effect on the photochemical oxidation of thiocyanates. In real water matrices (tap water and circulating water of the tailing dump of a gold mining plant), oxidative processes are significantly slowed down. In tap water, this effect is mainly due to the influence of hydrocarbonates, and in waste water, it is due to the multicomponent nature of the water matrix. The efficiency of wastewater treatment from thiocyanates was $100 \%$, for COD - $82 \%$, for dissolved organic carbon $-65 \%$. No cyanides were found after the treatment.
\end{abstract}

Keywords: thiocyanates, persulfate, destruction, photooxidation, anions, butyl xanthate, natural solar radiation, sulfate radical based - advanced oxidation process.

Acknowledgements. This work was supported by the Basic Research Program of Baikal Institute of Nature Management SB RAS (no. 0273-2021-0006) using the equipment of the CCU BINM SB RAS (Ulan-Ude, Russia).

Citation: Batoeva, A.A., Sizykh, M.R., Aseev, D. G. Effect of anions and related organic compounds on the kinetics of thiocyanate oxidation in a Solar-induced oxidative system. J. Sib. Fed. Univ. Chem., 2022, 15(1), 69-80. DOI: 10.17516/1998-2836-0272

(C) Siberian Federal University. All rights reserved

This work is licensed under a Creative Commons Attribution-NonCommercial 4.0 International License (CC BY-NC 4.0).

* Corresponding author E-mail address: abat@binm.ru, marisyz@binm.ru 


\title{
Влияние анионов и сопутствующих органических соединений \\ на кинетику окисления тиоцианатов \\ в Solar-индуцированной окислительной системе
}

\author{
А.А. Батоева, М.Р. Сизых, Д.Г. Асеев \\ Байкальский институт природопользования СО РАН \\ Российская Федерачия, Улан-Удэ
}

\begin{abstract}
Аннотация. Изучено влияние анионов (гидрокарбонатов, хлоридов, сульфатов) и органических соединений (ксантогенатов) на кинетику окисления тиоцианатов в фотоиндуцированной железоперсульфатной системе с использованием в качестве источника излучения естественного солнечного света. Установлено, что введение в раствор анионов ингибирует процесс деструкции тиоцианатов. Максимальное влияние оказывают гидрокарбонаты; так, при концентрации $\mathrm{HCO}_{3}^{-}$ 1 мМ время обработки, необходимое для полной деструкции тиоцианатов, увеличилось с 6 до 15.7 мин. При высоких концентрациях гидрокарбонатов ( $\geq 5$ мМ) эффективность окисления тиоцианатов не превышает $52 \%$. Введение в раствор бутилового ксантогената не оказывает существенного влияния на процесс фотохимического окисления тиоцианатов. В реальных водных матрицах (водопроводной воде и оборотной воде хвостохранилища золотоизвлекательной фабрики) окислительные процессы существенно замедляются. В водопроводной воде этот эффект обусловлен преимущественно влиянием гидрокарбонатов, а в сточной воде - многокомпонентным характером водной матрицы. Эффективность очистки сточных вод от тиоцианатов при этом составила $100 \%$, по ХПК - 82 \%, по растворенному органическому углероду - 65 \%. Цианиды в очищенной воде не обнаружены.
\end{abstract}

Ключевые слова: тиоцианаты, персульфат, деструкция, окисление, анионы, естественное солнечное излучение, комбинированные окислительные системы.

Благодарности. Работа выполнена в рамках государственного задания Федерального государственного бюджетного учреждения науки Байкальского института природопользования Сибирского отделения Российской академии наук (проект № 0273-2021-0006) с использованием оборудования ЦКП БИП СО РАН (Улан-Удэ).

Цитирование: Батоева, А.А. Влияние анионов и сопутствующих органических соединений на кинетику окисления тиоцианатов в Solar-индуцированной окислительной системе / А. А. Батоева, М. Р. Сизых, Д. Г. Асеев // Журн. Сиб. федер. унта. Химия, 2022, 15(1). C. 69-80. DOI: 10.17516/1998-2836-0272 


\section{Введение}

Проблема охраны водных объектов от техногенного загрязнения остается одной из самых актуальных уже несколько десятилетий. Для ее решения ведется активный поиск и разработка новых методов и технологий очистки производственных вод, позволяющих снизить поступление недостаточно очищенных стоков в экосистемы. Особое внимание при этом уделяется методам глубокой доочистки, среди которых лидируют передовые комбинированные окислительные процессы (Advanced Oxidation Processes (AOPs)), суть которых заключается в окислительной деструкции загрязнителей активными формами кислорода (АФК), формирующимися в растворе «in situ» [1-7]. Прекурсором АФК, как правило, является пероксид водорода - экологически чистый окислитель, при разложении которого образуется вода и кислород. Одной из причин, сдерживающих включение комбинированных окислительных методов с использованием пероксида водорода в технологические схемы очистки стоков, выступает неселективность основных АФК - гидроксильных радикалов, что приводит к значительному перерасходу окислителя вследствие нецелевых реакций с компонентами водных матриц (анионами, природным органическим веществом и т. д.). В связи с этим в последние годы возрос интерес исследователей к изучению возможности использования в комбинированных окислительных технологиях персульфатов как источников сульфатных анион-радикалов, сочетающих высокую окислительную способность $\left(\mathrm{E}_{0}=2.5-3.1 \mathrm{~B}\right)$ с большей селективностью [8-11]. Кроме того, продолжительность существования сульфатных анион-радикалов в растворе на три порядка больше, чем у гидроксильных радикалов [12], что позволяет добиться глубокого разложения больших органических молекул до простых неорганических веществ. Вследствие этого комбинированные окислительные процессы, основанные на использовании в качестве прекурсора АФК пероксидисульфатов или пероксомоносульфатов (Sulfate radical based - Advanced oxidation processes (SR-AOPs)), являются конкурентоспособными.

Для образования сульфатных анион-радикалов пероксодисульфаты активируют физическим воздействием (ультрафиолетовое излучение, ультразвук, повышение температуры и т. д.) или химически (переходные металлы, углеродсодержащие вещества и др.) [13]. При этом максимальная эффективность и глубокое окисление (минерализация) органических соединений достигаются при сочетании нескольких методов активации одновременно. Сведения о влиянии компонентов водных матриц (анионов и растворенного органического вещества) на кинетику процесса окисления органических соединений SR-AOPs носят противоречивый характер [14]. Отмечается, что анионы могут участвовать в процессах образования и трансформации АФК, влиять на стабильность окислителя и активность катализатора, а также образовывать новые соединения с продуктами реакции, иногда высокотоксичные [14]. Характер влияния анионов определяется как их концентрацией в растворе, так и природой окисляемых соединений. Так, например, при окислении смеси органических соединений, состоящей из бензола, толуола, этилбензола и ксиленов, термически активированным персульфатом установлено, что в присутствии хлоридов ингибируется деструкция бензола, а ксиленов - промотируется $\left(\left[\mathrm{Cl}^{-}\right]=\right.$ $=100-500 \mathrm{MM})[15]$.

В настоящее время в мировой литературе накоплен достаточно обширный материал, доказывающий перспективность использования фотоактивированных SR-AOPs методов для окислительной деструкции биорезистентных органических загрязнителей. В большинстве 
работ в качестве источников УФ-излучения используют ртутные лампы низкого и среднего давления [16]. Растет интерес исследователей к использованию полихроматического естественного солнечного излучения (Solar) для интенсификации окислительной деструкции стойких органических загрязнителей, инактивации патогенной микрофлоры [17]. Однако встречаются лишь единичные публикации по обезвреживанию токсичных неорганических поллютантов, в частности цианидов и тиоцианатов [18-20]. По нашему мнению, с точки зрения энергоэффективности и экологичности процессов данное направление исследований представляется весьма актуальным и для обезвреживания токсичных неорганических загрязнителей.

Ранее были изучены основные закономерности фотохимического окисления стойких неорганических соединений тиоцианатов, основных трудноокисляемых компонентов стоков производств по переработке упорных золотосодержащих руд, пероксодисульфатом, активированным излучением естественного солнечного света [20]. Установлено, что добавление в раствор ионов $\mathrm{Fe}^{3+}$ приводит к увеличению константы скорости реакции окисления тиоцианатов в 20 раз и полной их деструкции. Настоящая работа является продолжением исследования и посвящена изучению влияния анионов (гидрокарбонатов, хлоридов, нитратов, сульфатов), наиболее характерных для природных и сточных вод, и сопутствующих органических соединений (ксантогенатов) на кинетику фотохимической деструкции тиоцианатов в комбинированной окислительной системе Solar $/ \mathrm{S}_{2} \mathrm{O}_{8}{ }^{2-} / \mathrm{Fe}^{3+}$.

\section{Экспериментальная часть}

Исследования проводили на растворах тиоцианатов с концентрацией 100 мг/л (1.72 мМ), приготовленных на различных водных матрицах:

- дистиллированной воде $(\mathrm{pH}=5.7 \pm 0.2$, удельная электрическая проводимость $($ УЭП $)=2$ мкСм/см);

- водопроводной воде г. Улан-Удэ $(\mathrm{pH}=7.11 \pm 0.2$, УЭП $=237 \pm 7$ мкСм/см, жесткость $=2.61 \pm 0.39$ мг-экв/л, $\mathrm{HCO}_{3}{ }^{-}=128 \pm 14 \mathrm{мг} / л, \mathrm{~K}^{+}=1.25 \pm 0.21 \mathrm{мг} / л, \mathrm{Mg}^{2+}=9.73 \pm 0.20 \mathrm{мг} /$ л, $\mathrm{Cl}^{-}=0.30 \pm 0.04$ мг/л, $\mathrm{SO}_{4}^{2-}=16.58 \pm 2.16$ мг/л, $\mathrm{Fe}_{(\text {общ) }}=$ н/о, общий органический углерод $\left(\right.$ TOC) $=3.4 \pm 0.9 \mathrm{мг} / л, \mathrm{Ca}^{2+}=36.08 \pm 0.76 \mathrm{мг} /$ л, $\mathrm{Na}=9.33 \pm 1.59 \mathrm{мг} /$ л, $\mathrm{NO}_{3}{ }^{2-}=4.82 \pm 0.63 \mathrm{мг} /$ л, $\mathrm{NO}_{2}{ }^{2-}<0.1$ мг/л, $\mathrm{Al}<0.05 \mathrm{мг/л);}$

- реальной оборотной воде хвостохранилища цеха гидрометаллургии золотоизвлекательной фабрики $\left(\mathrm{pH}=10.35, \mathrm{SCN}^{-}=98 \mathrm{мг} / л,\left[\mathrm{Fe}(\mathrm{CN})_{6}\right]^{3-}\right]=6.50 \pm 1.82 \mathrm{мг} / л, \mathrm{NO}_{3}^{-}=8.73 \pm 2.01 \mathrm{мг} /$, $\mathrm{NH}_{4}{ }^{+}=4.99 \pm 1.50$ мг/л, ХПК=250 $\pm 37,5$ мг/л, ТОС $=62.78 \pm 9.42 \mathrm{мг/л,} \mathrm{Fe}_{\text {общ. }}=0.07 \pm 0.018$ мг/л, $\mathrm{Cu}^{2+}=20.06 \pm 4.01 \mathrm{мг/л).}$

В экспериментах использовали: $\mathrm{KSCN}, \mathrm{Fe}_{2}\left(\mathrm{SO}_{4}\right)_{3} \times 9 \mathrm{H}_{2} \mathrm{O}$ и $\mathrm{K}_{2} \mathrm{~S}_{2} \mathrm{O}_{8}(99 \%$ ), сульфат натрия, хлорид натрия, гидрокарбонат натрия (ООО «Химреактивснаб», Россия), технический бутиловый ксантогенат.

Натурные исследования («оpen-air») проводили без термостатирования в солнечные дни с мая по сентябрь 2020 г. в г. Улан-Удэ (51²8'47.747" с. ш. 1077'19.536" в. д.) на экспериментальной установке, подробно описанной ранее [21]. Скорость потока обрабатываемого раствора составляла 1 л/мин, объем - 1 л. Значения интенсивности солнечного излучения в диапазоне

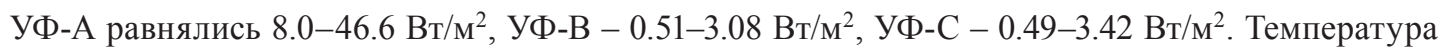


обрабатываемого раствора при проведении эксперимента постепенно увеличивалась и к окончанию эксперимента составляла $40 \pm 2{ }^{\circ} \mathrm{C}$.

Эксперименты проводили при оптимальных условиях, установленных ранее для полного фотоокисления тиоцианатов в железо-пероксодисульфатной системе с использованием в качестве источника излучения квазисолнечной лампы и естественного солнечного света - $\left[\mathrm{S}_{2} \mathrm{O}_{8}{ }^{2-}\right.$

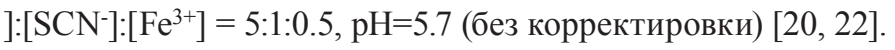

Содержание тиоцианатов в растворе контролировали фотометрическим экспресс-методом с азотнокислым железом [23].

Эффективность очистки сточных вод оценивали по изменению концентрации контролируемых компонентов по формуле

$$
\ni(\%)=\left(1-\frac{C_{\tau}}{C_{0}}\right) \times 100,
$$

где $\mathrm{C}_{0}$ и $\mathrm{C}_{\tau}$ - исходная и в момент времени $\tau$ (мин) концентрации соответственно.

Спектры поглощения растворов регистрировали на спектрофотометре UV-Vis Agilent 8453 с использованием кварцевой кюветы ( $1=1 \mathrm{~cm})$.

Для оценки эффективности очистки сточных вод использовали интегральные показатели - степень минерализации органических соединений и химическое потребление кислорода. Степень минерализации органических соединений оценивали по изменению содержания общего органического углерода, определяемого на приборе Shimadzu TOC-L CSN (Япония, предел обнаружения 50 мкг/л). Калибровку прибора проводили по стандартным образцам бифталата калия и двууглекислого натрия. ХПК определяли в реакторе ХПК DRB200 (Hach, Германия) с прямым считыванием результатов с помощью портативного колориметра DR / 890 (Насh, Германия).

Для сравнительной оценки результатов, полученных при естественном солнечном облучении в разные дни, принимали величину интенсивности солнечного излучения в диапазоне спектра А+В (280-400 нм) равной 30 Вт/м² , к которой нормализовывали все экспериментальные значения интенсивности в данном спектральном диапазоне [24]. Продолжительность экспозиции для каждой экспериментальной точки $\mathrm{t}_{30 \mathrm{~B} т}$, рассчитывали относительно интенсивности, «нормализованной» к $30 \mathrm{BT} / \mathrm{M}^{2}$ :

$$
\mathrm{t}_{30 \mathrm{BT}}=\mathrm{t}_{\mathrm{n}-1}+\Delta \mathrm{t}_{\mathrm{n}} \times \mathrm{I} / 30 \times\left(\mathrm{V}_{\mathrm{i}} / \mathrm{V}_{\mathrm{t}}\right),
$$

где $\mathrm{n}$ - номер экспериментальной точки отбора пробы; $\mathrm{t}_{\mathrm{n}-1}-$ продолжительность экспозиции в предыдущей точке отбора пробы; $\Delta \mathrm{t}_{\mathrm{n}}-$ изменение экспозиции между двумя точками отбора проб; I - интенсивность излучения в диапазоне $(\mathrm{A}+\mathrm{B})$ в момент отбора пробы в точке $n ; \mathrm{V}_{\mathrm{i}}-$ общий объем обрабатываемого раствора; $\mathrm{V}_{\mathrm{t}}$ - объем освещаемого раствора.

\section{Результаты и обсуждение}

Влияние анионов на процесс окислительной деструкции органических соединений в фотоSR-AOPs, протекающих по радикально-цепному механизму, обусловлен, прежде всего, их взаимодействием с АФК, в результате чего в растворе происходит формирование дополнительных радикальных частиц, что приводит либо к интенсификации процесса за счет повышения общего окислительного потенциала системы, либо к его замедлению вследствие межрадикальных взаимодействий, ведущих к обрыву цепи. 
Ранее было экспериментально доказано, что процесс фотохимического окисления тиоцианатов в Solar-индуцированной окислительной системе Solar $/ \mathrm{S}_{2} \mathrm{O}_{8}{ }^{2-} / \mathrm{Fe}^{3+}$ протекает по сопряженному ион-радикальному механизму с участием генерируемых in situ активных форм кислорода, преимущественно сульфатных анион-радикалов [20]. Введение в раствор гидрокарбонатов ингибирует процесс окисления тиоцианатов (рис. 1). При концентрации $\mathrm{HCO}_{3}^{-1}$ мМ время обработки, необходимое для полной деструкции тиоцианатов, возросло с 6 до 15.7 мин. Вероятно, это связано с нецелевым расходованием АФК вследствие их взаимодействия с гидрокарбонатами с высокой скоростью [25]:

$$
\mathrm{SO}_{4}^{-\cdot}+\mathrm{HCO}_{3}^{-} \rightarrow \mathrm{SO}_{4}^{2-}+\mathrm{CO}_{3}{ }^{--}+\mathrm{H}^{+} k=2.8 \times 10^{6} \mathrm{M}^{-1} \mathrm{C}^{-1}
$$

При высоких концентрациях гидрокарбонатов ( $\geq 5$ мМ) эффективность окисления тиоцианатов не превышает 52 \%. Причиной этому, вероятно, является «буферизация» раствора (рис. 1), которая приводит к разрушению железосодержащих комплексов. Ионы $\mathrm{Fe}^{3+}$ гидролизуются и дезактивируются. Полученные результаты хорошо согласуются с данными исследований по изучению влияния гидрокарбонатов на кинетику окисления органических соединений в железо-персульфатных системах [21, 26-28].

Добавление хлорид-ионов в диапазоне концентраций от 1 до 10 мМ существенного влияния на кинетику окисления тиоцианатов в комбинированной системе Solar $/ \mathrm{S}_{2} \mathrm{O}_{8}{ }^{2-}$ $\mathrm{Fe}^{3+}$ не оказывает (рис. 2). Во многих исследованиях по изучению влияния анионов на кинетику окисления органических соединений сульфатными анион-радикалами сообщается об ингибирующем эффекте хлоридов, особенно при их высоких концентрациях $[29,30]$. Одной из причин этого явления в железо-персульфатных системах называют способность хлоридов образовывать устойчивые комплексы с $\mathrm{Fe}^{3+}$, тем самым обрывать цикл восстановления железа в каталитической системе. Однако тиоцианатные комплексы

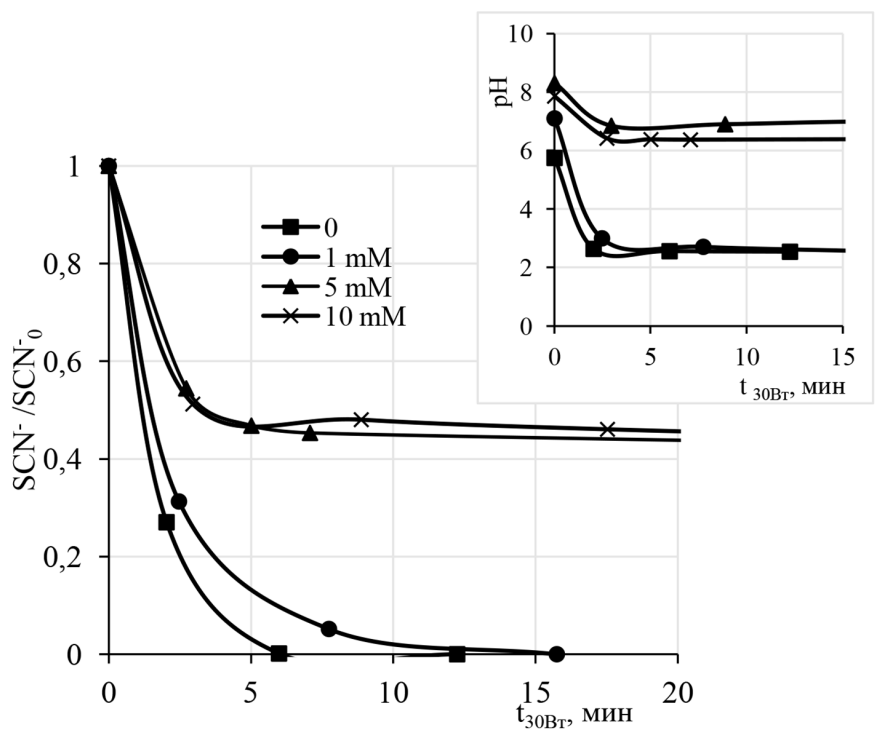

Рис. 1. Влияние гидрокарбонатов на кинетику окисления тиоцианатов

Fig. 1. Effect of hydrocarbonates on the kinetics of thiocyanate oxidation

$$
-74-
$$




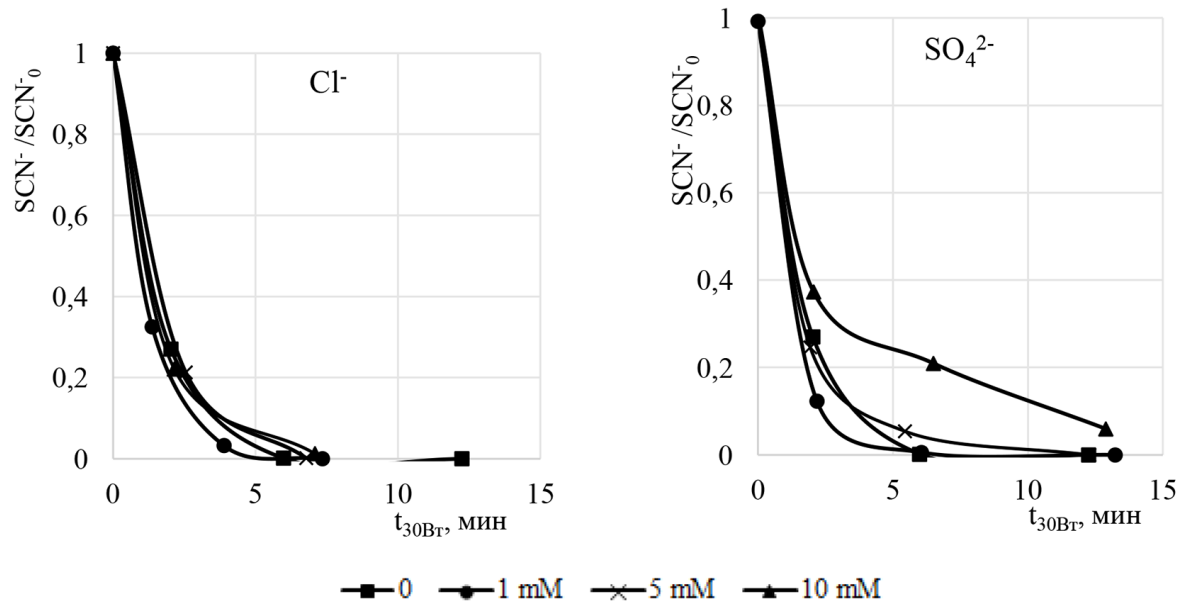

Рис. 2. Вляние хлоридов и сульфатов на кинетику окисления тиоцианатов

Fig. 2. Influence of chlorides and sulfates on the kinetics of thiocyanate oxidation

c Fe ${ }^{3+}$ более устойчивы, чем хлоридные, логарифм констант устойчивости составляет 3.23 и 1.01 соответственно [31], поэтому вероятность формирования новых комплексов в растворе низкая.

При окислении тиоцианатов в комбинированной системе Solar $/ \mathrm{S}_{2} \mathrm{O}_{8}{ }^{2-} / \mathrm{Fe}^{3+}$ при добавлении в раствор сульфатов с концентрацией 1 мМ начальная скорость реакции окисления возросла с 0.57 до 0.64 мМ/мин, однако время, необходимое для полного разложения таргетного соединения, не изменилось (рис. 2).

Интенсифицирующий эффект сульфатов ранее был обнаружен при окислительной деструкции хлорамфеникола фотоактивированным персульфатом [32]. Авторы предположили, что в присутствии сульфатов в растворе снижается вероятность протекания нецелевых реакций расходования АФК, в том числе взаимодействия сульфатных анион-радикалов с персульфатом:

$$
\mathrm{SO}_{4}{ }^{--}+\mathrm{S}_{2} \mathrm{O}_{8}{ }^{2-} \rightarrow \mathrm{S}_{2} \mathrm{O}_{8}{ }^{2--}+\mathrm{SO}_{4}{ }^{2-}
$$

Кроме того, несмотря на то, что сульфаты не реагируют с сульфатными анион-радикалами [15], они могут косвенным образом способствовать генерированию дополнительного количества $\mathrm{SO}_{4}{ }^{--}$вследствие протекания реакции [33]:

$$
\mathrm{HO}+\mathrm{SO}_{4}^{2-} \rightarrow \mathrm{SO}_{4}{ }^{--}+\mathrm{OH}^{-}
$$

Увеличение концентрации сульфатов до 10 мМ ингибирует процесс окисления тиоцианатов, начальная скорость реакции окисления снизилась до 0.49 мМ/мин, полной деструкции не наблюдалось (рис .2). Это может быть обусловлено нецелевым расходованием сульфатных анион-радикалов вследствие реакции рекомбинации, протекающей с высокой скоростью $\left(\mathrm{k}=3.1 \cdot 10^{8}\right.$ мин $\left.^{-1}\right)[34]$ :

$$
\mathrm{SO}_{4}{ }^{--}+\mathrm{SO}_{4}{ }^{--} \rightarrow \mathrm{S}_{2} \mathrm{O}_{8}{ }^{2-} .
$$


В процессе обогащения руд на предприятиях горноперерабатывающей промышленности в качестве флотореагентов широко используется бутиловый ксантогенат калия (калий О-бутил-дитиокарбонат) [35]. В процессе флотации большая часть ксантогенатов остается на поверхности флотируемого минерала и лишь незначительная их часть переходит в водную фазу, поэтому их концентрация в стоках составляет десятки миллиграммов в литре [36]. Экспериментально установлено, что введение в раствор бутилового ксантогената до 20 мг/л не оказывает существенного влияния на процесс фотохимического окисления тиоцианатов в комбинированной системе Solar/ $\mathrm{S}_{2} \mathrm{O}_{8}{ }^{2-} / \mathrm{Fe}^{3+}$ (рис. 3). При этом необходимо отметить, что ксантогенаты эффективно окисляются при прямом фотолизе (рис. 4).

Процессы окислительной деструкции загрязнителей в комбинированных окислительных системах в реальных водных матрицах - многокомпонентных природных и сточных водах, протекают значительно медленнее и зависят не только от концентраций анионов, но и от их взаимного влияния [37]. Установлено, что компоненты водопроводной воды ингибируют процесс фотохимического окисления тиоцианатов, начальная скорость реакции окисления снизилась в 2.3 раза (до $0.25 \mathrm{mM} / \mathrm{Mин)}$ ), время полной деструкции тиоцианатов составило 7.4 мин (рис. 5). Этот эффект обусловлен преимущественно присутствием в водной матрице гидрокарбонатов $\left(\mathrm{HCO}_{3}{ }^{-}=128\right.$ мг/л), так как характер кинетической кривой хорошо коррелирует с результатами, представленными выше, полученными при окислении тиоцианатов в модельных растворах (в дистиллированной воде) в присутствии гидрокарбонатов. Для нивелирования ингибирующего влияния $\mathrm{HCO}_{3}{ }^{-}$были выполнены эксперименты с корректировкой исходной реакции среды водопроводной воды до 4.5 (рис. 5). При этом начальная скорость реакции окисления тиоцианатов увеличилась (до 0.38 мМ/мин), время полной деструкции тиоцианатов составило 8.3 мин.

Оборотные воды хвостохранилища золотоизвлекательной фабрики (ЗИФ) имеют сложный многокомпонентный состав, характеризующийся значительным содержанием трудноокисляе-

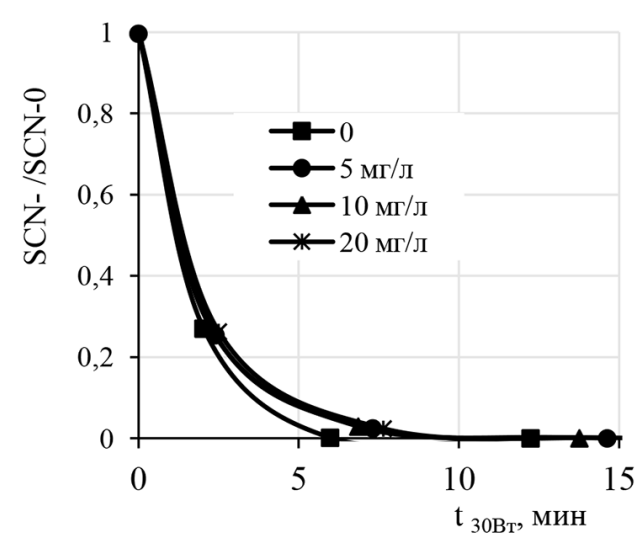

A

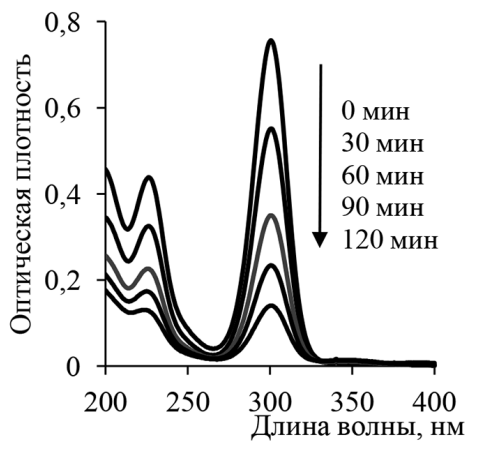

Б
Рис. 3. Влияние ксантогенатов на кинетику окисления тиоцианатов

Fig. 3. Influence of xanthates on the kinetics of thiocyanate oxidation
Рис. 4. Изменение спектров поглощения ксантогенатов при прямом фотолизе

Fig. 4. Changes in absorption spectra of xanthates during direct photolysis 


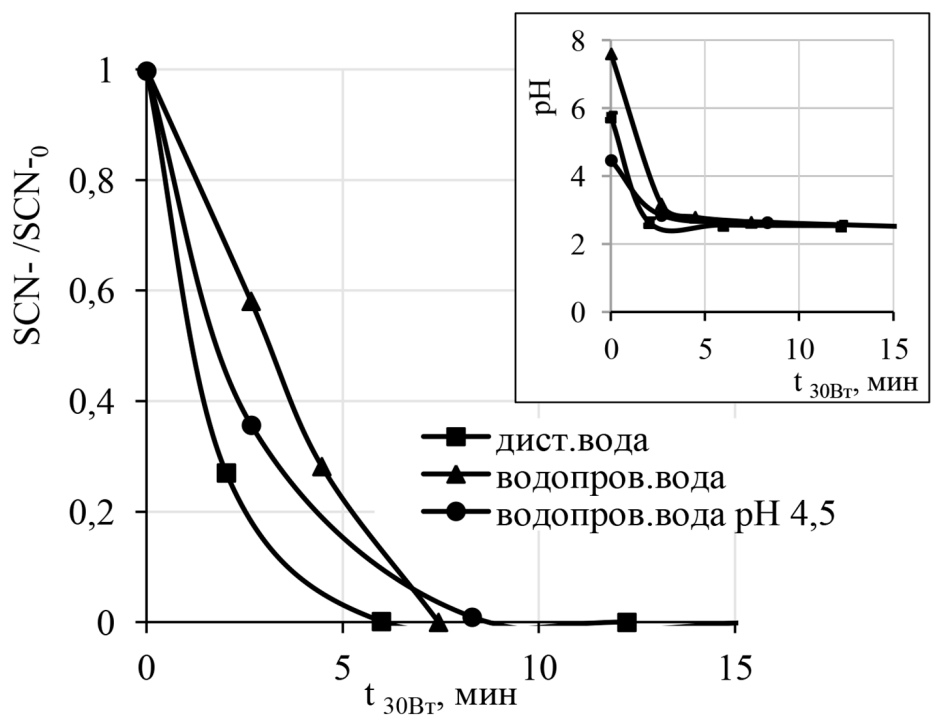

Рис. 5. Окисление тиоцианатов в водопроводной воде

Fig. 5. Oxidation of thiocyanate in tap water

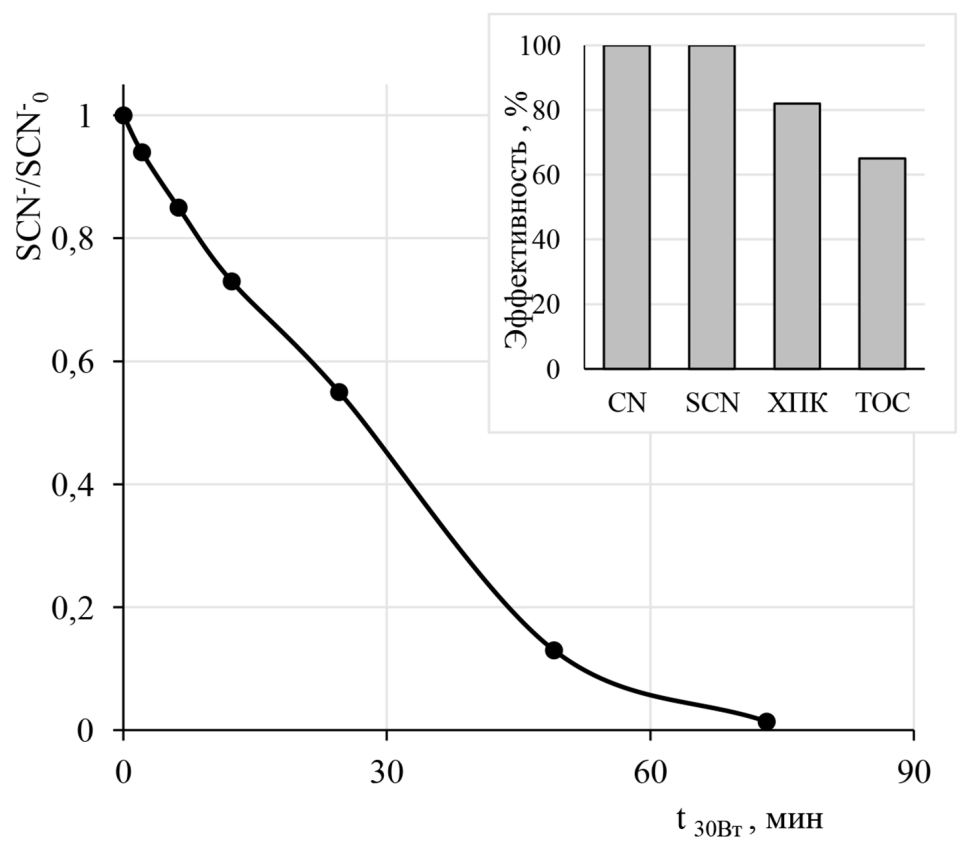

Рис. 6. Окисление тиоцианатов в оборотной воде хвостохранилища ЗИФ и эффективность ее очистки

Fig. 6. Oxidation of thiocyanate in the recycled water of the tailings dump and the treatment efficiency

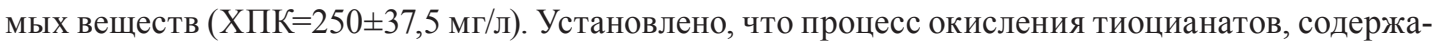
щихся в сточных водах ЗИФ, протекает медленнее, полной деструкции удается достичь лишь через 72 мин обработки (рис. 6). Однако при этом не происходит накопления токсичных продуктов реакции - цианидов, ХПК снижается на 82 \%, ТОС - на 65 \%. 
Таким образом, полученные результаты свидетельствуют о перспективности использования комбинированного метода, основанного на фотохимическом окислении загрязнителей в комбинированной системе Solar $/ \mathrm{S}_{2} \mathrm{O}_{8}{ }^{2-} / \mathrm{Fe}^{3+}$, где в качестве источника излучения используется естественный солнечный свет, для очистки сточных вод предприятий горнодобывающей промышленности, содержащих тиоцианаты.

\section{Заключение}

Изучено влияние сопутствующих анионов, наиболее характерных для реальных водных матриц (хлоридов, сульфатов, гидрокарбонатов), и органических загрязнителей (ксантогенатов) на эффективность протекания процессов фотохимической деструкции тиоцианатов в Solar-индуцированной окислительной системе Solar $/ \mathrm{S}_{2} \mathrm{O}_{8}{ }^{2-} / \mathrm{Fe}^{3+}$.

Установлено, что рассмотренные анионы ингибируют процесс деструкции тиоцианатов. Максимальное влияние оказывают гидрокарбонаты; так, при концентрации $\mathrm{HCO}_{3}{ }^{-1} \mathrm{MM}$ время обработки, необходимое для полной деструкции тиоцианатов, увеличилось с 6 до 15.7 мин. При высоких концентрациях гидрокарбонатов ( $\geq 5 \mathrm{MM})$ эффективность окисления тиоцианатов не превышает $52 \%$. Введение в раствор бутилового ксантогената (до 20 мг/л) не оказывает существенного влияния на процесс фотохимического окисления тиоцианатов в комбинированной Solar-индуцированной системе.

В реальной водной матрице - водопроводной воде - процесс окисления тиоцианатов существенно ингибируется, что обусловлено преимущественно влиянием гидрокарбонатов. В оборотной воде хвостохранилища ЗИФ окисление тиоцианатов происходит медленнее ввиду многокомпонентного характера водной матрицы, однако накопления токсичных продуктов - цианидов - не наблюдается, а интегральный показатель качества воды ХПК снижается на 62 \%.

\section{Список литературы / References}

1. Miklos D.B., Remy C., Jekel M., Linden K.G., Drewes J.E. and Hübner U. Evaluation of Advanced Oxidation Processes for Water and Wastewater Treatment: A Critical Review. Water Research 2018, Vol.139, P. 118-131.

2. Корниенко Г.В., Кенова Т.А., Корниенко В. Л., Кукушкин А. А. Непрямое электрокаталитическое окисление резорцина активными формами кислорода, in situ генерированными в сопряженных реакциях на анодах из $\mathrm{Pt}$ и $\mathrm{Pb} / \mathrm{PbO}_{2}$ и катоде из мезоструктурированного углерода СМК-3. Журн. Сиб. федер. ун-та. Химия 2021. Т. 14(1). С. 72-81. [Kornienko G. V., Kenova T. A., Kornienko V.L., Kukushkin A.A. Electrocatalytic resorcinol oxidation by active oxygen forms in situ generated in conjugate reactions on $\mathrm{Pt}$ and $\mathrm{Pb} / \mathrm{PbO}_{2}$ anodes and mesostructured carbon cathode CMK-3. J. Sib. Fed. Univ. Chem. 2021, Vol.14(1). P. 72-81 (in Russ.)].

3. Babu D.S., Srivastava V., Nidheesh P. V., Kumar M. S. Detoxification of water and wastewater by advanced oxidation processes. Sci. Total. Environ. 2019. Vol. 696. P. 133961].

4. Ma D., HuanY., Lai C. et al. Critical review of advanced oxidation processes in organic wastewater Treatment. Chemosphere 2021. Vol. 275. P. 130104.

5. Urbina-Suarez N.A., Machuca-Martínez F., Barajas-Solano A.F. Advanced Oxidation Processes and Biotechnological Alternatives for the Treatment of Tannery Wastewater. Molecules 2021. Vol. 26. P. 3222. 
6. Giwa A., Yusuf A., Balogun H. A. et al. Recent advances in advanced oxidation processes for removal of contaminants from water: A comprehensive review. Process Safety and Environmental Protection 2021. Vol.146. P. 220-256.

7. Dewil R., Mantzavinos D., Poulios I., Rodrigo M. A. New perspectives for advanced oxidation processes. J. Environ. Manage. 2017. Vol. 195. P. 93-99.

8. Giannakis S., Lin K. Y.A., Ghanbari F. A review of the recent advances on the treatment of industrial wastewaters by Sulfate Radical-based Advanced Oxidation Processes (SR-AOPs). Chem. Eng. J. 2021. Vol. 406, P. 127083.

9. Karim A. V., Jiao Y., Zhou M., Nidheesh P. V. Iron-based persulfate activation process for environmental decontamination in water and soil. Chemosphere 2021. Vol. 265. P. 129057.

10. Hou K., Pi Zh.., Yao F. et al. A critical review on the mechanisms of persulfate activation by iron-based materials: Clarifying some ambiguity and controversies. Chem. Eng. J., 2021. Vol. 407. P. 127078.

11. Ike I. A. Linden K. G, Orbell J. D., Duke M. Critical review of the science and sustainability of persulphate advanced oxidation processes. Chem. Eng. J. 2018. Vol. 338. P. 651-669.

12. Karim A.V., Jiao Y., Zhou M., Nidheesh P.V. Iron-based persulfate activation process for environmental decontamination in water and soil. Chemosphere 2021. Vol. 265. P. 129057. https://doi. org/10.1016/j.chemosphere.2020.129057

13. Wang J., Wang S. Activation of persulfate (PS) and peroxymonosulfate (PMS) and application for the degradation of emerging contaminants. Chem. Eng. J. 2018. Vol. 334. P. 1502-1517.

14. Wang J., Wang S. Effect of inorganic anions on the performance of advanced oxidation processes for degradation of organic contaminants. Chem. Eng. J. 2021. Vol. 411. P. 128392.

15. Ma J., Yang Y., Jiang X. et al. Impacts of inorganic anions and natural organic matter on thermally activated persulfate oxidation of BTEX in water. Chemosphere 2018. Vol.190. P. 296-306.

16. Yang J., Zhu M., Dionysiou D.D. What is the role of light in persulfate-based advanced oxidation for water treatment? Water Research2021. Vol.189. P. 116627.

17. Tsydenova O., Batoev V., Batoeva A. Solar-Enhanced Advanced Oxidation Processes for Water Treatment: Simultaneous Removal of Pathogens and Chemical Pollutants. Inter. J. of Environ. Research and Public Health. 2015. Vol.12. P. 9542-9561.

18. Duran A., Monteagudo J.M., Martín I. S., Aguirre S.M. Decontamination of industrial cyanide-containing water in a solar CPC pilot plant. Solar Energy 2010, Vol. 84, P. 1193-1200.

19. Pineda Arellano C.A., Silva Martınez S. Effects of $\mathrm{pH}$ on the degradation of aqueous ferricyanide by photolysis and photocatalysis under solar radiation. Solar Energy Materials and Solar Cells 2010. Vol. 94. P. 327-332.

20. Батоева А.А., Сизых М.Р., Мункоева В.А., Цыбикова Б.А. Перспективы использования солнечного излучения для обезвреживания цианидсодержащих сточных вод. Горный информационно-аналитический бюллетень 2021. № 7. С. 53-69. [Solar irradiation prospects in cyanide-bearing wastewater decontamination. Mining Informational and Analytical Bulletin 2021. (7). P. 52-69 (in Russ.)].

21. Khandarkhaeva M. et al. Oxidation of atrazine in aqueous media by solar- enhanced Fentonlike process involving persulfate and ferrous ion. Ecotoxicol. Environ. Saf. 2017. Vol. 137. P. 35-41. 
22. Batoeva A.A., Sizykh M.R., Munkoeva V.A. Photocatalytic Oxidation of Thiocyanates in Aqueous Solutions. Russian Journal of Applied Chemistry 2020. Vol. 93(2). P. 281-288.

23. Hovinen J., Lahti M., Vilpo J. Spectrophotometric Determination of Thiocyanate in Human Saliva. J. Chem. Educ. 1999. Vol. 76(9). P. 1281.

24. Jimenez M., Oller I., Maldonado M. I., Malato S., Hernandez-Ramirez A., Zapata A., PeraltaHernandez J. M. Solar photo-Fenton degradation of herbicides partially dissolved in water. Catalysis Today 2011. Vol. 161. P. 214-220.

25. Luo C., Ma J., Jiang J. et al. Simulation and comparative study on the oxidation kinetics of atrazine by $\mathrm{UV} / \mathrm{H}_{2} \mathrm{O}_{2}, \mathrm{UV} / \mathrm{HSO}_{5}{ }^{-}$and $\mathrm{UV} / \mathrm{S}_{2} \mathrm{O}_{8}{ }^{2-}$. Water Res. 2015. Vol. 80. P. 99-108.

26. Khandarkhaeva M., Batoeva A., Sizykh M. et al. Photo-Fenton-like degradation of bisphenol A by persulfate and solar irradiation. J. Environ. Manage. 2019. Vol. 249. P. 109348.

27. Lee J., von Gunten U., Kim J.-H., Persulfate-Based Advanced Oxidation: Critical Assessment of Opportunities and Roadblocks. Environ. Sci. Technol. 2020. Vol. 54. P. 3064-3081.

28. Yang Q., Ma Y., Chen F. et al. Recent advances in photo-activated sulfate radical-advanced oxidation process (SR-AOP) for refractory organic pollutants removal in water. Chem. Eng. J. 2019. Vol. 378. P. 122149.

29. Bi W., Wu Y., Wang X. et al. Degradation of oxytetracycline with $\mathrm{SO}_{4}{ }^{-}$under simulated solar light. Chem. Eng. J. 2016. Vol. 302. P. 811-818.

30. Sharma J., Mishra I. M., Dionysiou D. D., Kumar V. Oxidative removal of Bisphenol A by UV-C/peroxymonosulfate (PMS): Kinetics, influence of co-existing chemicals and degradation pathway. Chem. Eng. J. 2015. Vol. 276. P. 193-204.

31. Лурье Ю. Справочник по аналитической химии. М.: Химия, 1989. 448 с. [Lurie Yu. Handbook of Analytical Chemistry, Moscow: Chemistry, 1979. 448 p. (in Russ.)]

32. Ghauch A., Baalbaki A., Amasha M. et al. Contribution of persulfate in UV-254 nm activated systems for complete degradation of chloramphenicol antibiotic in water. Chem. Eng. J. 2017. Vol. 317. P. 1012-1025.

33. Antoniou M., de la Cruz A., Dionysiou D. Degradation of microcystin-LR using sulfate radicals generated through photolysis, thermolysis and e-transfer mechanisms. Appl. Catal. B-Environmental 2010. Vol. 96. P. 290-298.

34. Neta P., Huie R.E. Rate constants for reactions of nitrogen oxide $\left(\mathrm{NO}_{3}\right)$ radicals in aqueous solutions, J. Phys. Chem. 1986. Vol. 90. P. 4644-4648.

35. Авдохин В.М. Основы обогащения полезных ископаемых. М.: Издательство Московского государственного горного университета, 2006. 417 c. [Avdokhin V.M. Basics of mineral processing. Moscow: Publishing house of the Moscow State Mining University, 2006. 417 p. (in Russ.)]

36. Лурье Ю.Ю., Рыбникова А.И. Химический анализ производственных сточных вод. М.: Химия, 1974. 335 c. [Lurie Yu. Yu., Rybnikova A. I. Chemical analysis of industrial wastewater. Moscow: Chemistry, 1974. 335 p. (in Russ.)]

37. Al Hakim S., Jaber S., Zein Eddine N. et al. Degradation of theophylline in a UV254/PS system: Matrix effect and application to a factory effluent. Chem. Eng. J. 2020. Vol. 380. P. 122478. 